\title{
Event Study Test of Incorporating Earning Announcement on Share Price
}

\author{
Dr. A. Shanker Prakash \\ Lecturer, School of Management Sciences, Varanasi, U.P., India, Mobile Number 9795156800
}

\begin{abstract}
The concept of stock market efficiency has been one of the most dominant themes in financial research for explaining the share price behaviour and the increasing globalization of financial markets has given impetus to this concept in emerging markets as well. The study of stock market efficiency plays a crucial role of keeping investor's behavior intact with release of information viz. past historical prices, corporate announcements or events. This paper aims to study the relevance of event study or semi-strong informational efficiency of the Indian Stock Market. This paper tries to explore the speed and accuracy of incorporating corporate earnings and action into share prices. The underlying concept of event study is market must quickly and accurately react to public announcement of corporate earnings. The data used for the study are basically secondary in nature, which have been collected from the official websites of National Stock Exchange for the period from $1^{\text {st }}$ April 2008 to $31^{\text {st }}$ March 2010. The study is done on fifteen companies from the list of S\&P CNX Nifty. To accomplish the above objectives we relied on following tests Average Security Returns Variability (ASRV), Average Abnormal Returns (AAR), Cumulative Abnormal Returns (CAR) and Cumulative Average Abnormal Returns (CAAR).
\end{abstract}

JEL Classification: G14

Keywords: AAR, ASRV, CAAR, Corporate Actions, Event Study

\section{Introduction}

The present study pertains to deal with aspect of discussion on the empirical research conducted to test the validity of the semi-strong form of market efficiency. The market is efficient in the semistrong form if share prices fully reflect all the publicly available information, including information contained in the sequence of past prices.

In an efficient market, stock prices adjust instantaneously and in an unbiased manner to newly published information. That is, information such as announcement of earnings of a firm gets immediately impounded into its share prices. Therefore, in a semi-strong efficient market, no investor is expected to outperform the market consistently based on public information. However, this is not to suggest that investors expected average rate of return on a security investment is zero. In an efficient market, the expected rate of return is directly proportionate to the risk level of the security. For the securities with the same degree of the risks, the expected rate of return will also be the same. No investor can earn a return on security in excess of the expected rate of return for the risk class of that security determined by the market rate of return.

\section{Literature Review}

Fama, Fisher, Jensen and Roll were the fore runners in examining the semi-strong form of efficient market hypothesis. In fact they developed the methodology to test the validity of the semistrong form of the efficient market hypothesis and that has been used frequently by the researchers. By and large, abundant studies are available to examine different issues pertaining to semi-strong form of efficiency by taking one or more type of public information.

We concentrate mainly on the studies testing semi-strong form of efficiency. Several studies were conducted on the Indian markets and empirical evidence on the semi-strong form of efficiency indicates mixed results. Most of the studies rejected the hypothesis of semi-strong form of efficiency. They are Rao and Geetha (1996), Ariff and Marisetty (2003), Ansari and Mahmood (2007). With respect to public information, Srivastava (1968), Obaidullah (1992), Thomas and Shah (2001), Babu and Selvam (2006), Thirumalvalavan and Sunitha (2006) Malhotra et.al. (2007) and Raja et.al. (2009) supported the semi-strong form of efficiency.

Literatures that provide empirical evidence for a potential trend towards efficiency in international markets are mixed. For example, Fama et.al. (1969), Fama (1998), Robbani and Anantharaman (2002), Jones and Bacon (2007), Yalama and Celik (2008) found supporting the semistrong form of efficiency. Evidence for the inefficiency of stock markets, were obtained by Balaban 
et.al. (1996), Tarbelsi and Oueslati (2004) Hadi (2006), Guttler et.al. (2006), Ologunde et.al. (2006) and Dasilas (2009).

Thus, many literatures conducted tests on the semi-strong form of efficiency but could not reveal the same impression and that led us to test whether the Indian stock market counters the semi-strong form of efficiency or otherwise it provides good scope for investors to earn an abnormal return with respect to relevant public announcements.

\section{Specific Objectives}

This chapter is aimed to test the market price of share in response to date of declaration of accounting information empirically. The rationale of the study is to analyze how quickly, any public information dissemination meliorate the behaviour of different communities for the instance of fifteen blue chip shares. To fortify our assumptions, the study is done in nine different window periods with respect to the facility of electronic data interface introduced by NSE for public listed companies. The facility of electronic data interface means to announce all those important corporate actions and reports in the site of NSE in lieu of their own site. With the availability of electronic data interface, the relevant information is quickly responding to the market and thereby enhances the transparency as well as efficiency of the market.

The prime objective is to examine the information content of the quarterly earnings announcement made by the companies. In other specification, the study is aimed to examine the speed with which the quarterly earnings information is instantaneously and in an unbiased manner impounded into share price. To carry out the above objectives, the study is best fitted into the linear regression model to find the linear normal return of daily share prices of sample companies by using market model throughout window period.

\section{Specific Hypotheses}

To console the study of above objectives, we framed two set of hypothesis and tested the sample companies.

Set-I. For testing Average Security Returns Variability (ASRV), null and alternative hypothesis are as follows:

$\mathrm{H}_{0}$ : Security prices do not react to quarterly earnings announcement i.e. ASRV $=1$.

$\mathrm{H}_{1}$ : Security prices react apparently to quarterly earnings report i.e. ASRV $>1$.

Set-II. For testing Cumulative Average Abnormal Returns (CAAR), null and alternative hypothesis are as follows:

$\mathrm{H}_{0}$ : There is no reaction and hence the abnormal returns are zero. To aver, CAAR $=0$.

$\mathrm{H}_{1}$ : There is either positive or negative reaction to the announcement of quarterly earnings.

To aver, $\mathrm{CAAR} \neq 0$.

For each of abnormal returns in the subsequent part of analysis at their individualistic level, calculated $\mathrm{AR}, \mathrm{CAR}$ and CAAR - we will refine the null hypothesis.

$H_{0}$ : the abnormal return identified is not statistically different from zero.

According to the null hypothesis, the abnormal return observed is not induced by the event of interest and is only obtained by chance.

\section{Data}

The event of the study is earning announcement for the period from January 2008 to March 2010. For conducting the study, three sets of data are used in this chapter. The first set of data consists of quarterly earnings announced by the sample firms. This includes the dates on which Board of Directors Meet and approves accounts of the firm at the end of the quarter period for which earnings are announced. The second set of data consists of daily closing prices of the sample of stocks at the National Stock Exchange for the period covered by this study. The third set is collection of Nifty Index for the period of study. In the quarterly earnings report we have chosen all the four quarter announcements for the study, thus we have 9 window periods for the analysis as a whole.

Table 1 shows the different date on which earning announcement had been publicized. In the table, the date - month are presented under the column of their respective years e.g. 26-02 of ABB under column 2010 shows date of declaration of earning announcement on 26th of February. These dates are date of Board of Directors Meet to approve accounts of the firm at the end of the quarter period for which earnings are announced. For testing the informational efficiency at semi-strong level, the earnings announcement is one of the effective techniques which ameliorate the behaviour of investors effectively and instantly. 


\section{Event Date and Windows}

Public announcement date of accounting information (earning reports) is considered as zero date. The zero date is the date on which price-sensitive information has been released. For the study, the event window construed in respect of zero date giving a total of 50 observations by taking 19 days observation prior to zero date and 30 days observation after the announcement.

\section{Methodology}

The daily returns have been calculated for both individual securities as well as market index using the following equation:

$\mathrm{R}_{\mathrm{i}, \mathrm{t}}=\frac{P_{i, t}-P_{i, t-1}}{P_{i, t-1}}$

Where, $\mathrm{R}_{\mathrm{i}, \mathrm{t}}=$ Return on Security $\mathrm{i}$ on day $\mathrm{t}$ $\mathrm{P}_{\mathrm{i}, \mathrm{t}}=$ Closing Price of the security on day $\mathrm{t}$ of company $\mathrm{i}$

$\mathrm{P}_{\mathrm{i}, \mathrm{t}-1}=$ Opening Price of the security on day $\mathrm{t}$ of company i.

For the statistical models, the assumption that returns are jointly multivariate normal and independent and identically distributed through time is imposed. This distributional assumption is sufficient for the constant mean return model and market model has to be correctly specified. Different models are used for computing expected returns. Despite of all those models, the famous model is market model which is widely used by researchers.

The market model is concerned with the process that generates security prices. The market model assumes two types of events to produce the variability in security returns. The variability occurs either due to macro event or micro event. These two events substantially influence the share prices of firms.

In this study, we have used the market model assuming that security returns are a linear function of the general market movement to manifest expected return on a stock as given in the following equation:

$\mathrm{R}_{\mathrm{i}, \mathrm{t}}=\alpha_{\mathrm{i}+} \beta_{\mathrm{i}} \mathrm{R}_{\mathrm{mt}}+\varepsilon_{\mathrm{it}}$

Where, $R_{i, t}=$ observed daily return for the security ' $i$ ' on day ' $t$ '

$\alpha_{\mathrm{i}}=$ intercept for the security ' $\mathrm{i}$ '

$\beta_{\mathrm{i}}=$ beta factor for the security ' $\mathrm{i}$ '

$\mathrm{R}_{\mathrm{mt}}=$ observed daily return for the market index ' $\mathrm{m}$ ' on day' $\mathrm{t}$ '.

$$
\varepsilon_{\mathrm{it}} \sim \text { iid }\left(0, \sigma^{2}\right)
$$

Thus, the model hypothesizes a stochastic process that generates security returns. It separates the stochastic portion of a security return into two components, a systematic component $\left(\beta_{\mathrm{i}} \mathrm{R}_{\mathrm{mt}}\right)$ and a nonsystematic or individualistic component $\left(\varepsilon_{\mathrm{it}}\right)$. The systematic component measures the impact of macro event, the variability in general market movement and the individualistic component (also called error term) measures the impact of micro event on the rate of return of individual security. Thus, the error term is a firm specific component.

In testing the semi-strong form of market efficiency, the concern is whether all the publicly available information regarding a security is 'fully reflected' in its share price so rapidly that there is no possibility to earn abnormal returns by using it. More formally, testing the semi-strong form of efficiency implies testing a martingale model in the following form:

$\mathrm{E}\left(\mathrm{AR}_{\mathrm{j}, \mathrm{t}+1} \mid \varphi\right)=0$

Where $A R_{j, t+1}$ is the abnormal return produced by security ' $\mathrm{j}$ ' at time ' $\mathrm{t}+1$ ' and $\varphi$ is the information set available at ' $t$ ', i.e. the date of announcement of the information for the company.

Abnormal Return $=$ Actual Return - Expected Return

The abnormal returns of the company have been calculated by getting the difference of actual returns over expected returns. Then, these calculated abnormal returns are averaged for their respective quarter that is nine quarters in this study for a particular sample company. To serve the purpose of our study, we cumulated all the available average abnormal returns (AAR) for their respective lags known as Cumulative Average Abnormal Returns (CAAR). The significance of CAAR is tested through t-statistics. The reaction in the security prices to the announcement of an information item is studied in this chapter with the help of Security Returns Variability (SRV) model. SRV model can be calculated as the square of abnormal returns to the variance of abnormal returns of window period. Further, SRV for the entire nine quarters were averaged to yield the Average Security Returns Variability (ASRV). Again, the significance of reaction in ASRV is applied using t-statistics on the value of (ASRV-1). 
While computing the average abnormal returns (AAR) it is to be remembered that the average effect of the announcement looked at rather than examining each company separately because other events occurring and averaging across all companies should minimize the effect of other events, thereby allowing a better examination of the event under study. For computation of cumulative average abnormal return, the individual day's average abnormal return (AAR) is added together from the beginning of the period to some specified period and is tested for significance.

For subsequent part of the study at its individualistic level, following methodology is used.

$\operatorname{CAR}\left(\mathbf{t}_{1}, \mathbf{t}_{2}\right)=\sum$ AR

Finally, we will calculate the cumulated average abnormal return around event as:

$\operatorname{CAAR}\left(\mathbf{t}_{1}, \mathbf{t}_{2}\right)=\frac{\operatorname{CAR}\left(\mathrm{t}_{1}, \mathrm{t}_{2}\right)}{\mathrm{N}}$

Where $\mathrm{N}$ is the sample size (15 events).

\section{Empirical Results}

The parameters of the market model have been estimated for 3 years pertaining to the sample companies under study. The study is executed for the period from January 2008 to March 2010 whereas the parameters of the market model have been determined for the period from 2007 to 2010 on daily return basis, to have compounded effect on the parameter of the market model. The alpha $(\alpha)$ and beta $(\beta)$ of each sample company is exhibited in the following table:

The above parameters have been gratified into the regression model with respect to the return of market index. The outcomes are compared against the actual returns of the sample companies' to determine the abnormal return of market for the window period.

The Table 3 shows the value of ASRV with t-value respectively for blue-chip companies. ASRV is showing how efficiently, the information regarding earning announcement impound in the share price returns. In an informational efficient market, the ASRV is expected to be one. It is inferred from the table that the ASRV on day 0 was $1.46,47$ percent greater than the average, and on day 1 it was 2.07 which was 108 percent greater than the average. The t-test clearly provides a clue that the prices of the securities are not significantly reacted to the announcement, particularly, to surrounding to the event day. This implies that the security prices of blue-chip companies reacted to the announcement of quarterly earnings on the next day (day 1 ) to the day of quarterly earnings announcement. However, the average ASRV during the period of 50 days was 0.99. The average ASRV during the 19 preannouncement days was 1.07 and average ASRV during post-announcement period of 30 days was 0.94 . This shows the quick adjustment of share price to the event of earning announcement during the postannouncement period leaving no scope for investors to earn an abnormal return. Moreover, the average ASRV during the period of 7 days (from day-3 to day 3 ), was 1.33 .

In an extension of the study, the reaction of ASRV is reported in Table 4 for respective days. From the above table the highest insignificant ASRV is 1.771114 for 0 to 1 day following this figure the subsequent highest ASRV are found during -12 to 1 day, -1 to 1 day, -2 to 2 day, -1 to 0 day then -7 to 7 day. This shows that investors are much aware of the event but due to presence of severe competition they had no scope to earn an abnormal return.

Figure 2 shows ASRV curve for 50 days. The ASRV curve is steeply rising on day 0 and day 1 . The days which ASRV exceeded one during the pre-announcement period are: $(-18,-17,-16,-15,-14$, $13,-12,-10,-8,-6,-5,-3,-2$ and -1$)$. However, the sharp upward drift in the ASRV following zero date reveals the fact that the market is not able to capture the information before its announcement. Therefore, the market is said to be near efficient.

The change in magnitude of share price with respect to public information is represented in the form of AAR shown in Table 5. The AAR shows the relationship between the magnitudes of change in earnings to that of price change. The AAR is expected to be zero in case of semi-strong form of efficient market. In this study, it is found that AAR is close to zero as 0.000833 and remains close to zero up to the announcement date. On $6^{\text {th }}$ day of post-announcement period the magnitude of AAR is about 0.002343 and that rose to around 0.006103 on $27^{\text {th }}$ day of post-announcement period. Moreover, average AAR for the 50 day window period is -0.0003 . The significant AAR on announcement day exhibits the AAR is induced by interest of event. The AAR is found to be negative for 11 days and 17 days in the pre-announcement and post-announcement periods respectively.

Following figure (Fig. 3) shows the AAR for 50 days. The figure provides a clue that returns on share price is quickly adjusting to the information date which one is pre-decided date so that the investors became much cautious to that of their trading rules leading AAR towards zero.

The same table further reveals the cumulative average abnormal returns across different companies for their respective days of pre-announcement and post-announcement window period. As regards to the 
CAAR, it is assumed that it should be zero before the announcement day and then a shift to a positive level (or negative level) depending on good or bad news right after the event and remains at that level in an efficient market. The CAAR is 0.000833 at 19 days pre-announcement period and cumulated for the entire 30 days post-announcement window period where average abnormal returns cumulated up to 0.01464. The CAAR is found to be very close to zero from two days prior to the event date and showed little adjustment of profit up to the event date. The coefficient of CAAR close to zero on event date shows the market is nearly semi-strong form efficient. The coefficient of CAAR after announcement date is started declining and found to be much consistent in negative trend. The negative trend appeared due to the infrequent trading observed and adjusted within the event window, it is possible that the results are contaminated.

\section{Scrip wise CAAR result}

More particularly, for each event of 15 companies we cumulated abnormal return at different moments in time inside the event window, from the whole 50 days CAR to only $(-1$ to +1$)$ CAR, very close to zero day.

The results obtained computing the AR for the 15 event samples shows that daily AR values are both positive and negative. We expected that the values of AR around the event day would be positive and statistically different from zero.

The excess of return calculated within the event window is non-zero at $1 \%$ meaning that there is a $99 \%$ probability that the observed returns are generated by the event of interest. This is very strong evidence showing that the market reacts to the announcement of earning information and incorporates the new available information immediately.

This can be seen from the CARs calculated within the event window and shown in Table 6 (i) and (ii) respectively.

The CAR computed for the event window (-15 to 15 ) reveals the fact that for some of events, there is a negative AR. On an average, the CAAR is $-3.96 \%$ and quite distant from zero which might be due to the reason of the event window being too long.

This is why the examination of CAAR is done by reducing the event window around the event day zero to (-10 to 10). It is observed that, although some of the events still register negative CAR and CAAR decreased to -4.01 $\%$, still this figures register the same fact as described above. In order to get consistency with positive results further reductions of the event window to (-5 to 5), (-3 to 3), (-2 to 2$)$ and (-1 to 1$)$ have been done. We observed improvements in the level of CAAR obtained, $-0.99 \%$ for the (-1 to 1$)$. In the above tables, all the value of CARs for respective cumulated periods is non-significant except for companies ABB and BPCL. Thus, it is noteworthy that all companies except $\mathrm{ABB}$ and BPCL are not statistically different from zero and thus follows the semi-strong form of efficiency.

As we expected, the more we cluster around the event day, the higher positive the market reaction is. This demonstrated that the market reacts quickly to new information regarding earning announcement, and there is evidence of semi-strong market efficiency.

\section{Conclusion}

This study intensively provides a look over the testing of semi-strong form efficiency in Indian Stock Market with respect to blue-chip companies for the period from January 2008 to March 2010. Two popular testing tools have been employed to reap the result whether the Indian investors could earn some abnormal return with response to information at their early stage or reflecting some delays. For conducting the above tests, we have employed two popular techniques. These are average security returns variability (ASRV) and tests of abnormal returns called average abnormal returns (AAR) and cumulative average abnormal returns (CAAR). Further scrip-wise analysis of cumulative abnormal return (CAR) is conducted to strengthen the result.

The results of all the techniques employed in the study are briefly corroborated as follows:

1. The ASRV study of 50 window day periods showed that the market is much reactive to the announcement of information. The average ASRV is very close to 1 and sharp upward drift on announcement date shows that market is semi-strong efficient.

2. In an extended study of ASRV, reaction of market is not significant and market is not leaving any scope for investors to earn abnormal returns.

3. For studying the change in magnitude of share price we had employed AAR test which revealed that AAR is significant for 9 days out of which AAR is also found to be significant at announcement date showing that the market is able to capture the information quickly. 
4. The consideration is not complete until we have a look over CAAR which showed that the CAAR is close to zero before announcement date and after announcement the CAAR curve is found to be much consistent at negative trend.

5. The scrip wise study at individual level is also comprised of CAR and CAAR tests. The results of CAR for companies are found not significantly different from zero with exception of ABB and BPCL companies. Further, CAAR is getting closer to zero as we approach towards the event day (-1 to 1 day).

In nut-shell, we have concluded that the scrips of Blue-chip companies are much consistently performing in the market and leave no scope for investors and equally prove the market is in the track of semi-strong form efficiency.

\section{References}

[1]. Raja M., Sudhahar J.C. and Selvam M., 2009, "Testing the Semi-Strong form Efficiency of Indian Stock Market with Respect to Information Content of Stock Split Announcement - A study in IT Industry", International Research Journal of Finance and Economics, Issue 25.

[2]. Ranganatham M. and Subramanian V., 1993, "Weak Form Efficient Markets Hypothesis: A Spectral Analytic Investigation", Vikalpa, Vol.18 No.2, 25-30.

[3]. Rao and Geetha, 1996, "Indian Capital Market- Informational Signalling and Efficiency", A.P.H. Publishing Corporation, New Delhi.

[4]. Rao, 1997, "Response of Stock Prices to Macroeconomic Events”, Finance India, Vol. XI No. 4, 881 -918.

[5]. Robbani M. G. and Anantharaman S., 2002, “An Econometric Analysis of Stock Market Reaction to Political Events in Emerging Markets" Second Annual ABIT Conference, Pittsburgh, Pennsylvania.

[6]. Samanta G.P. and Bordoloi S., 2005 "Predicting Stock Market- An Application of Artificial Neural Network Technique through Genetic Algorithm" Finance India Vol. XIX No.1, 173-188.

[7]. Sarkar N. and Mukopadhyay D., 2002, "Testing Market Efficiency in the Framework of Model Specification: An Empirical Investigation with Indian Data", ERU Discussion Paper Series, ERU/2002 -03.

[8]. Sarma S.N., 2004,"Stock Market Seasonality in an Emerging Market", Vikalpa, Vol. 29 No. 3,35 -41.

[9]. Seiler and Rom, 1997, "A Historical Analysis of Market Efficiency: Do Historical Returns Follow a Random Walk?" Journal of Financial and Strategic Decisions, Vol.10 No.2, 49-57.

[10]. Selvam M. and Babu K.A., 2009, “Analysis of Quarterly Earnings Announcement and Informational Efficiency of Indian Capital Market”, Finance India, Vol. XXIII No.2, 575-604.

\section{Tables}

Table 1: Date of Earning Announcement by Selected Companies

\begin{tabular}{|c|c|c|c|c|c|c|c|c|c|}
\hline Dates & 2010 & \multicolumn{4}{|c|}{2009} & \multicolumn{4}{|c|}{2008} \\
\hline ABB & $26-02$ & $30-10$ & $31-07$ & $30-04$ & $20-02$ & $24-10$ & $25-07$ & $25-04$ & $19-02$ \\
\hline BPCL & $28-01$ & $29-10$ & $28-07$ & 29-05 & $29-01$ & $30-10$ & $28-07$ & $17-06$ & $31-01$ \\
\hline CIPLA & $28-01$ & $28-10$ & $29-07$ & 24-04 & $22-01$ & $22-10$ & $18-07$ & $25-04$ & $24-01$ \\
\hline GAIL & $18-01$ & $28-10$ & $24-07$ & $12-06$ & $28-01$ & $23-10$ & 29-07 & $13-05$ & $31-01$ \\
\hline H.HONDA & $25-01$ & $21-10$ & $29-07$ & $21-04$ & $20-01$ & $21-10$ & $29-07$ & $24-04$ & $31-01$ \\
\hline J.STEL & $28-01$ & $31-10$ & $29-07$ & $27-05$ & 29-01 & $30-10$ & $25-07$ & $27-05$ & $28-01$ \\
\hline K.BANK & $21-01$ & $27-10$ & $28-07$ & $12-05$ & $22-01$ & $31-10$ & $28-07$ & 09-05 & $21-01$ \\
\hline R.CAPITAL & $31-01$ & $30-10$ & $31-07$ & $30-04$ & $20-01$ & $31-10$ & $30-07$ & 29-04 & 24-01 \\
\hline SAIL & $27-01$ & $22-10$ & $30-07$ & $28-05$ & $27-01$ & $21-10$ & 21-07 & $16-05$ & $29-01$ \\
\hline SBIN & $25-01$ & $31-10$ & $30-07$ & 09-05 & $24-01$ & $27-10$ & $26-07$ & $02-05$ & $24-01$ \\
\hline SIEMENS & $29-01$ & $26-11$ & $23-07$ & $30-04$ & $30-01$ & $25-11$ & $22-07$ & $25-04$ & $31-01$ \\
\hline T.MOTORS & $29-01$ & $26-10$ & $27-07$ & 29-05 & $30-01$ & $31-10$ & $30-07$ & $28-05$ & $31-01$ \\
\hline T.POWER & 19-01 & $29-10$ & $30-07$ & $28-05$ & 29-01 & $27-10$ & $25-07$ & $23-06$ & $29-01$ \\
\hline T.STEEL & $28-01$ & $27-10$ & $29-07$ & $25-06$ & $28-01$ & $24-10$ & $31-07$ & $26-06$ & $31-01$ \\
\hline WIPRO & $20-01$ & $27-10$ & $22-07$ & $22-04$ & 21-01 & $22-10$ & $18-07$ & $18-04$ & $18-01$ \\
\hline
\end{tabular}

Table 2: Estimated Market Parameters for Selected Scrips

\begin{tabular}{|l|l|l|l|}
\hline S.N. & Name of the Company & Alpha $(\boldsymbol{\alpha})$ & Beta ( $\boldsymbol{\beta})$ \\
\hline 1 & ABB Ltd. & -0.00174 & 0.597664 \\
\hline 2 & Bharat Petroleum Corporation Ltd. & -0.00099 & 0.390819 \\
\hline 3 & Cipla Ltd. & -0.00074 & 0.322527 \\
\hline 4 & GAIL (India) Ltd. & -0.00101 & 0.616835 \\
\hline 5 & Hero Honda Motors Ltd. & 0.001484 & 0.270421 \\
\hline 6 & Jindal Steel \& Power Ltd. & 0.001691 & 0.972841 \\
\hline 7 & Kotak Mahindra Bank Ltd. & -0.00217 & 0.972321 \\
\hline 8 & Reliance Capital Ltd. & -0.00304 & 1.187301 \\
\hline
\end{tabular}


Event Study Test Of Incorporating Earning Announcement On Share Price

\begin{tabular}{|l|l|l|l|}
\hline 9 & State Bank of India & -0.00173 & 0.762782 \\
\hline 10 & Steel Authority of India Ltd. & -0.00101 & 1.021979 \\
\hline 11 & Siemens Ltd. & -0.00163 & 0.664512 \\
\hline 12 & Tata Motors Ltd. & -0.00292 & 0.767004 \\
\hline 13 & Tata Power Co. Ltd. & 0.000707 & 0.722853 \\
\hline 14 & Tata Steel Ltd. & -0.00202 & 0.971285 \\
\hline 15 & Wipro Ltd. & -0.00119 & 0.657876 \\
\hline
\end{tabular}

Table 3: Analysis of ASRV for Blue-chip Shares

\begin{tabular}{|c|c|c|}
\hline DAYS & Average Security Return Variability & T-test values \\
\hline-19 & $0.807913 * *$ & -1.932 \\
\hline-18 & 1.090929 & 0.739 \\
\hline-17 & 1.10532 & 0.863 \\
\hline-16 & 1.049012 & 0.350 \\
\hline-15 & $1.191902 * * *$ & 1.460 \\
\hline-14 & 1.308081 & 0.957 \\
\hline-13 & 1.081473 & 0.620 \\
\hline-12 & 1.139893 & 0.831 \\
\hline-11 & 0.977017 & -0.156 \\
\hline-10 & 1.045135 & 0.310 \\
\hline-9 & 0.871516 & -1.232 \\
\hline-8 & 1.036635 & 0.302 \\
\hline-7 & 0.97434 & -0.120 \\
\hline-6 & $1.227582 * * *$ & 1.360 \\
\hline-5 & 1.238665 & 1.056 \\
\hline-4 & $0.866386^{* * * *}$ & -1.561 \\
\hline-3 & 1.076666 & 0.545 \\
\hline-2 & 1.177909 & 0.694 \\
\hline-1 & 1.025825 & 0.187 \\
\hline 0 & 1.465098 & 2.060 \\
\hline 1 & $2.07713 *$ & 3.970 \\
\hline 2 & 1.388313 & 1.927 \\
\hline 3 & 1.074137 & 0.572 \\
\hline 4 & 1.111217 & 0.637 \\
\hline 5 & 0.938741 & -0.672 \\
\hline 6 & 1.023873 & 0.125 \\
\hline 7 & 1.039709 & 0.135 \\
\hline 8 & 1.090471 & 0.633 \\
\hline 9 & 1.170751 & 0.904 \\
\hline 10 & 1.148726 & 0.934 \\
\hline 11 & 0.892355 & -0.509 \\
\hline 12 & $0.825123 * *$ & -1.870 \\
\hline 13 & $0.667627^{*}$ & -3.763 \\
\hline 14 & $0.664003 * *$ & -3.324 \\
\hline 15 & 1.048197 & 0.278 \\
\hline 16 & $0.759727 * *$ & -1.824 \\
\hline 17 & $0.722082 * *$ & -3.300 \\
\hline 18 & $0.758045^{* * *}$ & -1.662 \\
\hline 19 & $0.765864^{* *}$ & -2.132 \\
\hline 20 & 0.923871 & -0.495 \\
\hline 21 & 0.817682 & -0.992 \\
\hline 22 & $0.637684 * *$ & -3.013 \\
\hline 23 & $0.821745^{* *}$ & -1.992 \\
\hline 24 & $0.679418^{* *}$ & -2.302 \\
\hline 25 & $0.78905^{* *}$ & -2.050 \\
\hline 26 & $0.814513 * *$ & -2.724 \\
\hline 27 & 1.154914 & 0.706 \\
\hline 28 & 0.841317 & -1.106 \\
\hline 29 & $0.8274 * * *$ & -1.655 \\
\hline 30 & $0.664798^{*}$ & -5.179 \\
\hline
\end{tabular}

*Significant at 0.01 level $\quad * *$ Significant at 0.05 level $\quad * * *$ Significant at 0.10 level.

Table 4: Analysis of Reaction of ASRV

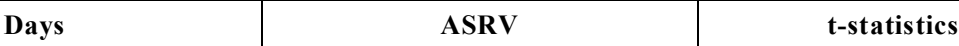


Event Study Test Of Incorporating Earning Announcement On Share Price

\begin{tabular}{|c|c|c|}
\hline-1 to 1 & 1.522684 & 1.715 \\
\hline-2 to 2 & 1.426855 & 2.370 \\
\hline-7 to 7 & 1.180373 & 2.358 \\
\hline-12 to 1 & 1.157128 & 1.906 \\
\hline-19 to 30 & 0.997916 & -0.059 \\
\hline-1 to 0 & 1.245462 & 1.118 \\
\hline 0 to 1 & 1.771114 & 2.520 \\
\hline
\end{tabular}

Table 5: Analysis of AAR and CAAR for Blue-chip Shares

\begin{tabular}{|c|c|c|c|}
\hline DAYS & AAR & T-TEST VALUE & CAAR \\
\hline-19 & 0.000833 & 0.374 & 0.000833 \\
\hline-18 & 0.00334 & 1.319 & 0.004173 \\
\hline-17 & -0.00138 & -0.446 & 0.00279 \\
\hline-16 & 0.001861 & 0.723 & 0.004651 \\
\hline-15 & 0.002645 & 1.188 & 0.007296 \\
\hline-14 & 0.001602 & 0.825 & 0.008898 \\
\hline-13 & -0.0022 & -0.703 & 0.0067 \\
\hline-12 & $-0.00576^{* *}$ & -2.514 & 0.000936 \\
\hline-11 & 0.002642 & 0.992 & 0.003578 \\
\hline-10 & 0.001221 & 0.512 & 0.004799 \\
\hline-9 & -0.00223 & -0.750 & 0.002569 \\
\hline-8 & -0.00129 & -0.482 & 0.001276 \\
\hline-7 & -0.00113 & -0.421 & 0.000145 \\
\hline-6 & -0.00024 & -0.207 & $-9.2 \mathrm{E}-05$ \\
\hline-5 & $-0.00627 * *$ & -2.374 & -0.00636 \\
\hline-4 & 0.003816 & 1.623 & -0.00254 \\
\hline-3 & -0.00346 & -1.048 & -0.00601 \\
\hline-2 & $-0.0048 * *$ & -2.156 & -0.0108 \\
\hline-1 & -0.00227 & -1.262 & -0.01307 \\
\hline 0 & $-0.00544 * * *$ & -2.105 & -0.0185 \\
\hline 1 & -0.00227 & -0.629 & -0.02078 \\
\hline 2 & -0.00172 & -0.487 & -0.02249 \\
\hline 3 & -0.00126 & -0.857 & -0.02375 \\
\hline 4 & -0.00108 & -0.413 & -0.02483 \\
\hline 5 & -0.00025 & -0.113 & -0.02507 \\
\hline 6 & 0.002343 & 0.794 & -0.02273 \\
\hline 7 & -0.00178 & -0.677 & -0.02451 \\
\hline 8 & -0.00332 & -0.955 & -0.02783 \\
\hline 9 & -0.00167 & -0.475 & -0.0295 \\
\hline 10 & $-0.00706 * * *$ & -1.990 & -0.03656 \\
\hline 11 & 0.002857 & 0.994 & -0.0337 \\
\hline 12 & 0.003871 & 1.265 & -0.02983 \\
\hline 13 & -0.00153 & -0.937 & -0.03136 \\
\hline 14 & $-4.7 \mathrm{E}-05$ & -0.024 & -0.03141 \\
\hline 15 & -0.0036 & -1.488 & -0.035 \\
\hline 16 & 0.000344 & 0.167 & -0.03466 \\
\hline 17 & 0.003491 & 1.270 & -0.03117 \\
\hline 18 & 0.002042 & 1.414 & -0.02913 \\
\hline 19 & -0.00292 & -1.049 & -0.03204 \\
\hline 20 & 0.000998 & 0.316 & -0.03105 \\
\hline 21 & 0.002048 & 1.491 & -0.029 \\
\hline 22 & -0.00041 & -0.237 & -0.02941 \\
\hline 23 & $0.005605 * *$ & 2.556 & -0.0238 \\
\hline 24 & -0.00318 & -1.415 & -0.02698 \\
\hline 25 & $0.006431 *$ & 3.145 & -0.02055 \\
\hline 26 & $0.005259 * *$ & 2.159 & -0.01529 \\
\hline 27 & $0.006103^{* * *}$ & 1.920 & -0.00919 \\
\hline 28 & -0.00447 & -1.694 & -0.01366 \\
\hline 29 & 0.000791 & 0.368 & -0.01287 \\
\hline 30 & -0.00177 & -0.640 & -0.01464 \\
\hline
\end{tabular}

$*$ Significant at 0.01 level $\quad * *$ Significant at 0.05 level $\quad * * *$ Significant at 0.10 level.

Table 6(i): CAR and CAAR around Zero Date

(Figures are in \%)

\begin{tabular}{|r|r|r|r|r|r|r|r|}
$\begin{array}{r}\text { CAR } \\
\text { to 15) }\end{array}$ & t-test & $\begin{array}{r}\text { CAR } \\
\text { (-10 to 10) }\end{array}$ & t-test & $\begin{array}{r}\text { CAR } \\
(-5 \text { to 5) }\end{array}$ & t-test & $\begin{array}{r}\text { CAR } \\
(-3 \text { to 3) }\end{array}$ & t-test \\
\hline
\end{tabular}


Event Study Test Of Incorporating Earning Announcement On Share Price

\begin{tabular}{|c|c|c|c|c|c|c|c|c|}
\hline ABB & -4.98 & -1.00 & -5.25 & -1.29 & -7.08 & $-2.58 *$ & -3.71 & -1.35 \\
\hline BPCL & -5.34 & -0.69 & -8.77 & -1.30 & -0.82 & -0.15 & -2.11 & -0.43 \\
\hline CIPLA & -5.94 & -1.36 & -3.50 & -1.11 & -3.78 & -1.56 & -2.44 & -1.20 \\
\hline GAIL & -3.32 & -0.65 & -5.29 & -1.21 & -6.15 & -1.99 & -3.85 & -1.34 \\
\hline HEROHONDA & 0.290 & 0.06 & 0.32 & 0.07 & 2.65 & 0.80 & 0.93 & 0.38 \\
\hline JINDALSTEL & -1.27 & -0.19 & 2.28 & 0.40 & 0.53 & 0.12 & 0.74 & 0.33 \\
\hline KOTAKBANK & -2.00 & -0.28 & -1.65 & -0.28 & 1.84 & 0.56 & -1.36 & -0.59 \\
\hline RELCAPITAL & -10.81 & -1.59 & -14.05 & $-3.10 *$ & -7.16 & -2.11 & -5.09 & -1.64 \\
\hline SAIL & -8.53 & -1.59 & -6.06 & -1.26 & -2.22 & -0.86 & -2.34 & -1.06 \\
\hline SBIN & -1.40 & -0.31 & -0.72 & -0.21 & -1.16 & -0.36 & -2.23 & -0.76 \\
\hline SIEMENS & -2.52 & -0.32 & -4.13 & -0.61 & -5.27 & -1.12 & -3.35 & -0.82 \\
\hline TATAMOTOR & -6.27 & -0.92 & -10.91 & -1.94 & -5.03 & -1.72 & -4.99 & -2.33 \\
\hline TATAPOWER & -0.36 & -0.07 & -0.24 & -0.05 & -2.78 & -0.95 & -2.94 & -1.50 \\
\hline TATASTEEL & -10.61 & -2.52 & -5.41 & -1.56 & -2.25 & -1.13 & -0.04 & -0.02 \\
\hline WIPRO & 3.65 & 0.67 & 3.22 & 0.62 & 1.24 & 0.31 & 1.03 & 0.27 \\
\hline CAAR & -3.96 & & -4.01 & & -2.49 & & -2.12 & \\
\hline
\end{tabular}

Table 6(ii): CAR and CAAR around Zero Date

\begin{tabular}{|c|c|c|c|c|c|c|}
\hline & $\begin{array}{r}\text { CAR } \\
(-2 \text { to } 2)\end{array}$ & t-test & $\begin{array}{r}\text { CAR } \\
\text { (-1 to } 1)\end{array}$ & t-test & $\begin{array}{r}\text { CAR } \\
(-1 \text { to } 3)\end{array}$ & t-test \\
\hline $\mathrm{ABB}$ & -2.64 & -0.93 & -0.43 & -0.16 & -2.53 & -0.89 \\
\hline BPCL & 1.80 & 0.47 & 0.21 & 0.32 & 2.07 & 0.57 \\
\hline CIPLA & -2.61 & -1.34 & -1.37 & -0.65 & -1.86 & -0.92 \\
\hline GAIL & -3.43 & -1.28 & -2.05 & -0.71 & -1.92 & -0.67 \\
\hline HEROHONDA & -1.59 & -1.41 & -0.66 & -0.56 & -0.17 & -0.11 \\
\hline JINDALSTEL & 1.13 & 0.51 & 0.51 & 0.23 & 1.23 & 0.56 \\
\hline KOTAKBANK & -1.59 & -0.82 & -0.12 & -0.06 & -1.60 & -0.83 \\
\hline RELCAPITAL & -2.31 & -0.91 & -2.09 & -0.91 & -1.85 & -0.75 \\
\hline SAIL & -2.31 & -1.06 & 0.19 & 0.20 & -1.89 & -0.85 \\
\hline SBIN & -2.57 & -0.89 & -2.70 & -1.57 & -3.58 & -1.71 \\
\hline SIEMENS & -5.55 & -1.89 & -3.36 & -1.06 & -3.26 & -0.94 \\
\hline TATAMOTOR & -2.60 & -1.56 & -0.30 & -0.31 & -2.31 & -1.40 \\
\hline TATAPOWER & -3.10 & -1.78 & -2.96 & -2.03 & -3.27 & -1.95 \\
\hline TATASTEEL & 0.21 & 0.13 & 0.86 & 1.45 & 0.93 & 0.98 \\
\hline WIPRO & 2.48 & 0.71 & -0.65 & -0.21 & 0.62 & 0.18 \\
\hline CAAR & -1.64 & & -0.99 & & -1.29 & \\
\hline
\end{tabular}

XII. Figures

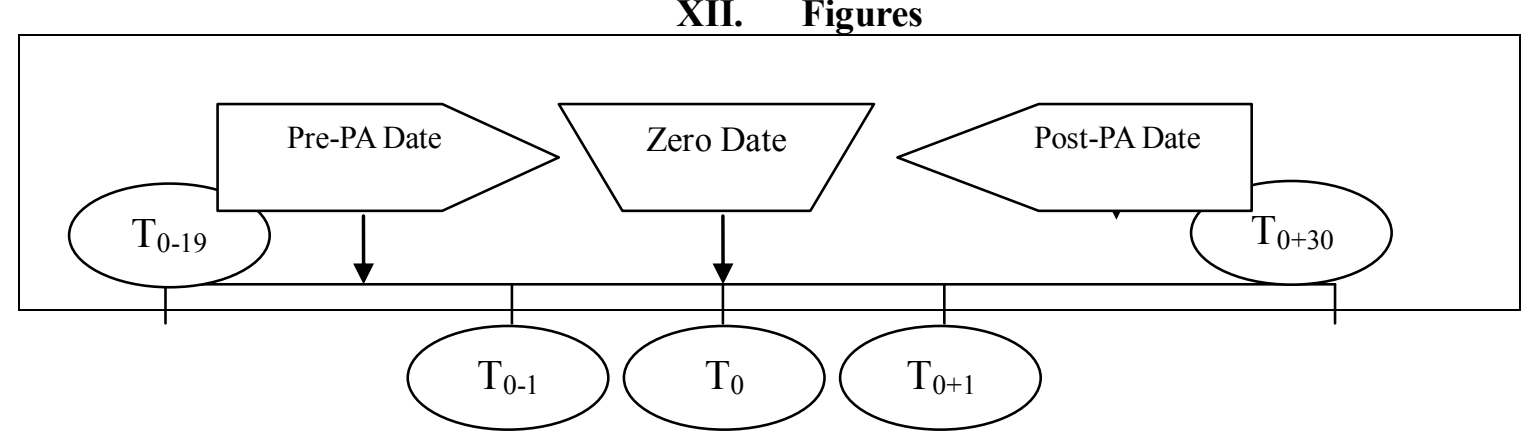

Fig. 1: Event Window Considered for the Study 


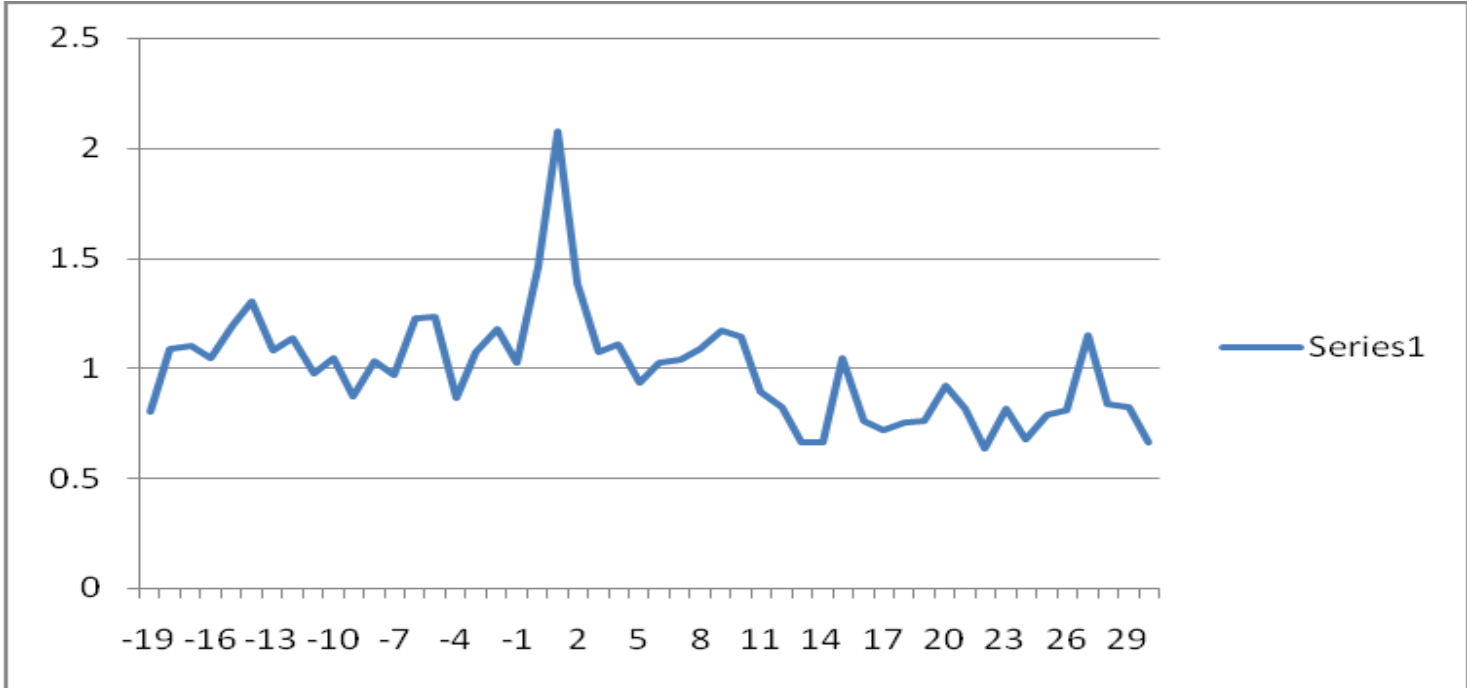

Figure 2: ASRV around Accounting Information Date

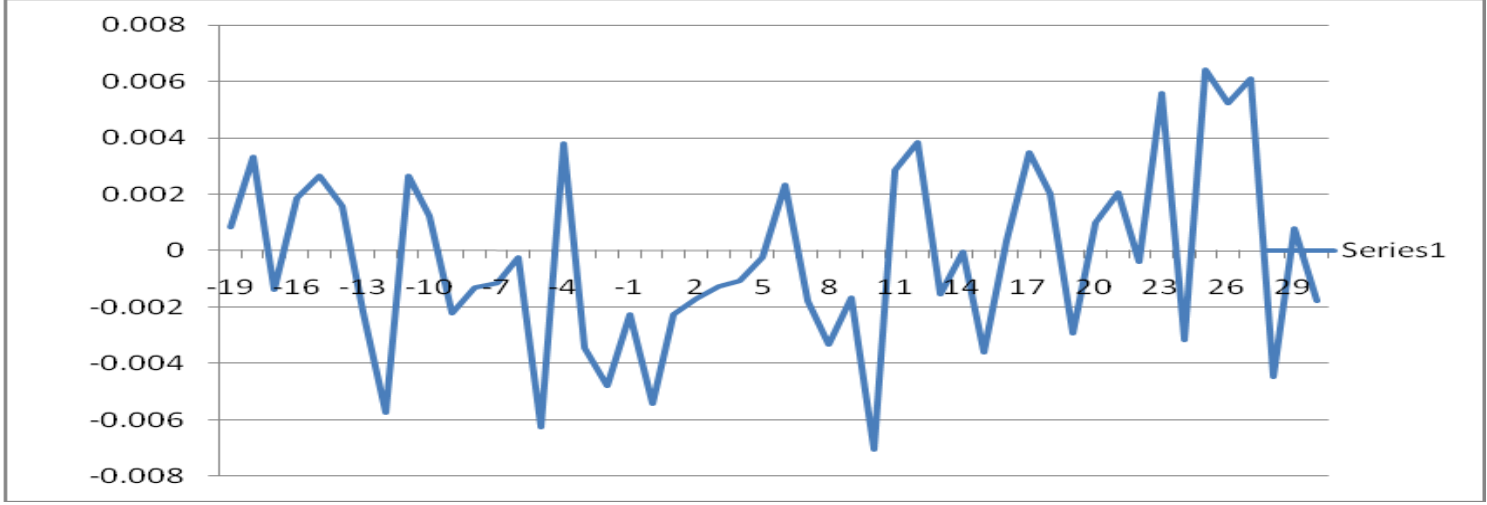

Figure 3: AAR around Accounting Information Date

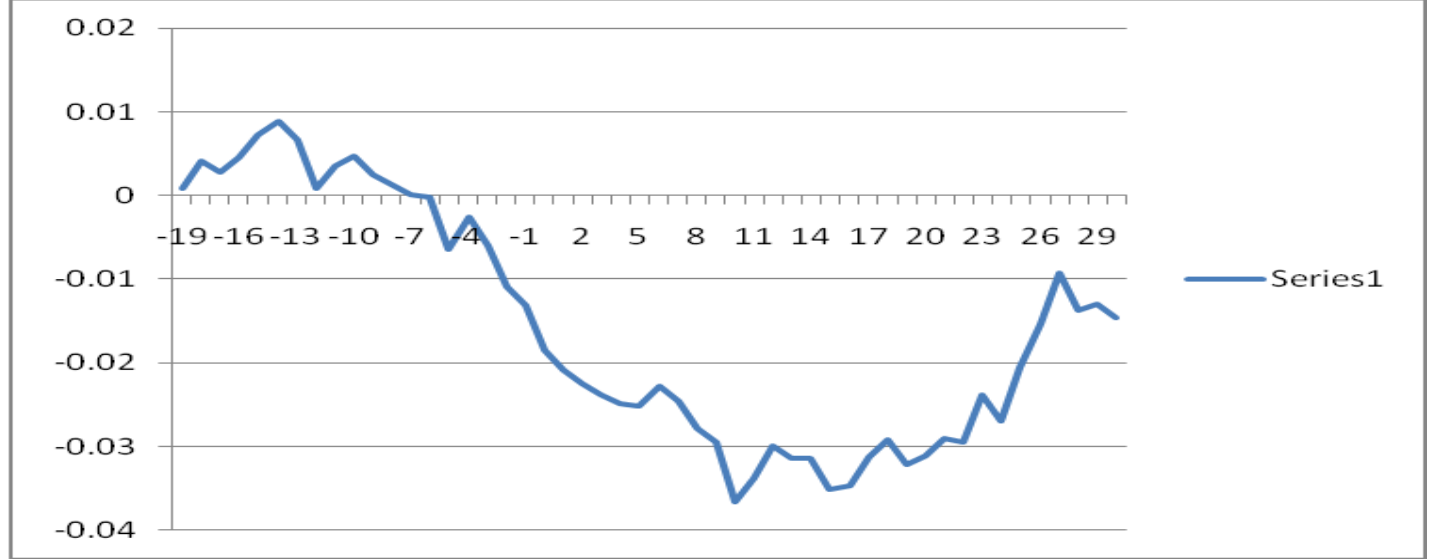

Figure 4: CAAR around Accounting Information Date 